\title{
What Is the Mean Procedure Time to Optimize Colonoscopy?
}

\author{
Taehyun Kim and Beom Jae Lee \\ Division of Gastroenterology, Department of Internal Medicine, Korea University Medical Center, Guro Hospital, Seoul, Korea
}

See "Predicting Colonoscopy Time: A Quality Improvement Initiative" by Deepanshu Jain, Abhinav Goyal, Stacey Zavala, on page 555-559.

Colonoscopy is the most effective and popular method for the screening, prevention, and diagnosis of colorectal cancer worldwide. However, there have been concerns on the ability of colonoscopy to detect adenoma. Colonoscopic examination is limited in this regard even if lesions are not missed because of variables such as the endoscopist's skill, experience, and the degree of bowel preparation. Thus, it is crucial to maintain and optimize the quality of colonoscopy.

Several quality indicators for colonoscopy are recommended: adenoma detection rate (ADR), the degree of bowel preparation, cecal intubation rate, and withdrawal time.

Adequate procedure time is a prerequisite for adenoma detection. In 2006, Barclay et al. reported that a minimum withdrawal time of 6 minutes enabled adequate adenoma detection during screening or diagnostic colonoscopy. ${ }^{1}$ This has become the principal guideline of diagnostic colonoscopy and most current guidelines now recommend this minimal time of 6 minutes to avoid missing adenoma during colonoscopy.

In this issue of the journal, Jain et al. tried to define the pre-procedure factors affecting colonoscopy procedure time. ${ }^{2}$ They retrospectively analyzed 1,239 patients undergoing screening colonoscopy using variables including age, sex, body mass index (BMI), previous abdominal surgery history,

Received: October 21, 2016 Revised: November 7, 2016

Accepted: November 10, 2016

Correspondence: Beom Jae Lee

Division of Gastroenterology, Department of Internal Medicine, Korea University Medical Center, 148 Gurodong-ro, Guro-gu, Seoul 08308, Korea

Tel: +82-2-2626-3004, Fax: +82-2-853-1943, E-mail: L85210@korea.ac.kr

(c) This is an Open Access article distributed under the terms of the Creative Commons Attribution Non-Commercial License (http://creativecommons.org/ licenses/by-nc/3.0) which permits unrestricted non-commercial use, distribution, and reproduction in any medium, provided the original work is properly cited. procedure timing, indication, and endoscopist experience. Total procedure time was significantly shorter in patients who underwent afternoon colonoscopy. Other factors including sex and history of surgery did not affect the procedure time. Using multiple regression analysis, the authors created a total procedure time prediction model. This model approaches the procedure time from the perspective of patient satisfaction or anxiety while awaiting colonoscopy. Jain et al. state that this prediction model might help to decrease the waiting time and improve the patient's satisfaction with the colonoscopy. ${ }^{2}$

However, the results of this study have raised some issues for readers to consider. First, the ADR is not shown. Adequate ADR is an indicator for high quality colonoscopy. After assessing and analyzing colonoscopy procedure time, the starting point and pre-condition status determined whether the enrolled patients underwent adequate colonoscopy. We could not evaluate the relationship between ADR and procedure time in this study. Second, it is not clear whether a prolonged or shortened procedure time is caused by delayed insertion or withdrawal time. Adequate colonoscopy procedure time is a prerequisite for optimized colonoscopy. Several factors affect colonoscopy procedure time. Patient factors include age, sex, BMI, constipation, the degree of bowel preparation status, history of abdominopelvic surgery. Additionally, the experience and characteristics of the endoscopist can affect the procedure time. ${ }^{3,4}$ A prolonged procedure time is usually defined by the cecal intubation time and reflects a difficult examination. However, increased procedure time due to difficult insertion can lead to several negative effects on colonoscopy quality including the increased chance of missing a lesion, fatigue of the endoscopist, and prolonged waiting time. Yang et al. ${ }^{5}$ reported that longer cecal intubation time was associated with lower 
ADR. They analyzed 12,679 patients who underwent screening colonoscopy. A shorter insertion time was associated with increased detection of small-sized polyps. ${ }^{5}$ In this study, afternoon colonoscopy was the significant factor affecting total procedure time. Colonoscopies in the afternoon had a shorter procedure time. Why did afternoon colonoscopy result in a shorter procedure time? Was it related to delayed insertion or shorter withdrawal time? The reason was not clarified in this study. It is still debated whether the timing of colonoscopy affects the ADR. Teng et al. recently reported that morning colonoscopy improved ADR and increased withdrawal time. ${ }^{6}$ Furthermore, Shinde et al. showed that there was no significant difference in ADR between morning and afternoon colonoscopy in haft -day block. Previous studies have shown that endoscopists have a tendency to withdraw the scope more quickly if the colonoscopy is performed in the afternoon. One possible reason is the desire to finish the colonoscopy quickly. Pressure to finish faster. ${ }^{8}$ Another possible reason is endoscopist fatigue causing a decline in the ADR. ${ }^{9}$ This study showed that the time needed for diagnostic colonoscopy was significantly shorter than that of screening/surveillance colonoscopy, which is an interesting finding. Although we could not evaluate the reason for this time difference because of lack of data, the procedure time difference may be the result of quick withdrawal of the scope by the endoscopist after an expected lesion is detected. A well-designed study in the future could achieve interesting results regarding the relationship of ADR, endoscopist technique, and indications.

This study evaluated a novel procedure time prediction model with the following questions: Can we use this model in the clinical fields? Is this model really valuable to the clinical practice? How is predicting colonoscopy procedure time beneficial? An adequately aliquoted number of patients could be helpful to maintain a high-quality colonoscopy with consideration to the endoscopist's physical condition. Additionally, it could shorten procedure delay and waiting time. What is the effect of procedure delay on the quality of colonoscopy? Keswani et al. ${ }^{10}$ reported that procedure delay and increased waiting time were not associated with a lower ADR. Waiting time is getting longer. ${ }^{10}$ In the era of conscious-sedation endoscopy, colonoscopy-associated pain and discomfort has been considerably decreased. However, from the bowel preparation to procedure, colonoscopy still causes fear, anxiety, and both physical and emotional discomfort. To make the colonoscopy comfortable for the patient, several methods have been suggested. Music $^{11}$ and clothes to decrease the patient's shame, ${ }^{12}$ and various relatively comfortable laxatives were suggested. The reason to improve the patient's satisfaction is the desire to increase follow-up study adherence by the patients. Predicting procedure time and the shortening of waiting time bench in waiting area can be the starting points for lowering patient's anxiety and increasing comfort during colonoscopy, which could increase follow-up study adherence. ${ }^{13}$

Finally, colonoscopy should be performed within the quality indicators. Optimizing procedure time may be a starting point for improving colonoscopy quality and will be helpful to improve patient satisfaction.

\section{Conflicts of Interest}

The authors have no financial conflicts of interest.

\section{REFERENCES}

1. Barclay RL, Vicari JJ, Doughty AS, Johanson JF, Greenlaw RL. Colonoscopic withdrawal times and adenoma detection during screening colonoscopy. N Engl J Med 2006;355:2533-2541.

2. Jain D, Goyal A, Zavala S. Predicting Colonoscopy Time: A Quality Improvement Initiative. Clin Endosc 2016;49:555-559.

3. Bernstein C, Thorn M, Monsees K, Spell R, O'Connor JB. A prospective study of factors that determine cecal intubation time at colonoscopy. Gastrointest Endosc 2005;61:72-75.

4. Zuber-Jerger I, Endlicher E, Gelbmann CM. Factors affecting cecal and ileal intubation time in colonoscopy. Med Klin (Munich) 2008;103:477481.

5. Yang MH, Cho J, Rampal S, et al. The association between cecal insertion time and colorectal neoplasm detection. BMC Gastroenterol 2013;13:124.

6. Teng TY, Khor SN, Kailasam M, Cheah WK, Lau CC. Morning colonoscopies are associated with improved adenoma detection rates. Surg Endosc 2016;30:1796-1803.

7. Shinde T, Singh S, Gupta M, Aoun E, Dhawan M. Adenoma Detection Rate is Not Influenced by the Timing of Colonoscopy. Am J Gastroenterol 2011;106:S158-S158.

8. Keswani RN, Taft TH, Coté GA, Keefer L. Increased levels of stress and burnout are related to decreased physician experience and to interventional gastroenterology career choice: findings from a US survey of endoscopists. Am J Gastroenterol 2011;106:1734-1740.

9. Lee CK, Cha JM, Kim WJ. Endoscopist Fatigue May Contribute to a Decline in the Effectiveness of Screening Colonoscopy. J Clin Gastroenterol 2015;49:e51-e56.

10. Keswani RN, Gawron AJ, Cooper A, Liss DT. Procedure Delays and Time of Day Are Not Associated With Reductions in Quality of Screening Colonoscopies. Clin Gastroenterol Hepatol 2016;14:723-728.e2.

11. Rudin D, Kiss A, Wetz RV, Sottile VM. Music in the endoscopy suite: a meta-analysis of randomized controlled studies. Endoscopy 2007;39:507-510.

12. Chung SH, Park SJ, Hong JS, et al. Comparison of double pants with single pants on satisfaction with colonoscopy. World J Gastroenterol 2013;19:4177-4184.

13. Pontone S, Tonda M, Brighi M, Florio M, Pironi D, Pontone P. Does anxiety or waiting time influence patients' tolerance of upper endoscopy? Saudi J Gastroenterol 2015;21:111-115. 